Document downloaded from:

http://hdl.handle.net/10251/62110

This paper must be cited as:

Pérez Ruiz, R.; Jiménez Molero, MC.; Sáez Cases, JA.; Miranda Alonso, MÁ. (2014). Cycloreversion of beta-lactams via photoinduced electron transfer. Organic and Biomolecular Chemistry. 12(42):8428-8432. doi:10.1039/c4ob01416b.

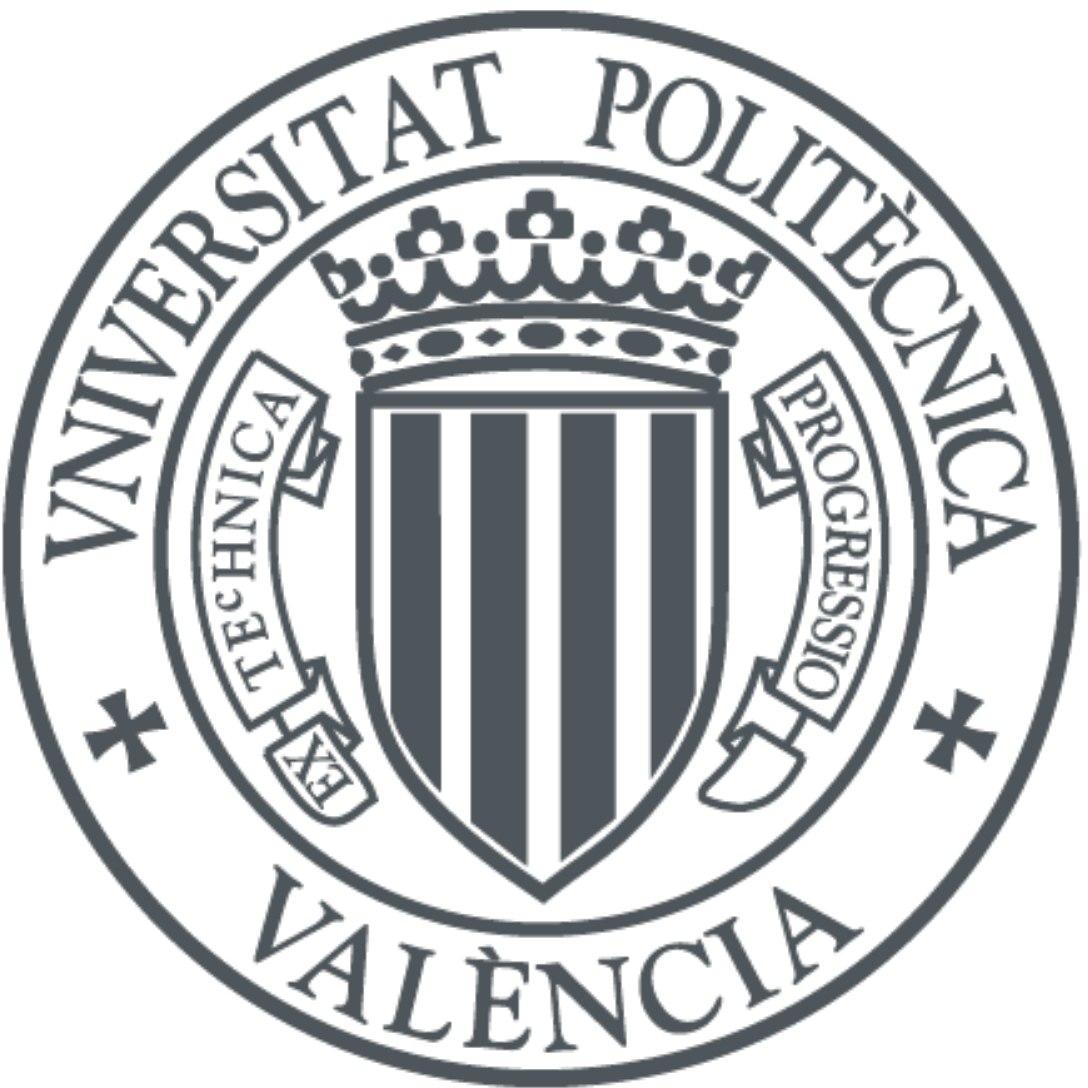

The final publication is available at

http://dx.doi.org/10.1039/c4ob01416b

Copyright Royal Society of Chemistry

Additional Information 


\title{
Cycloreversion of $\beta$-Lactams via Photoinduced Electron Transfer
}

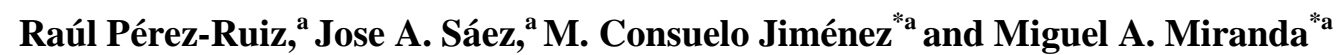

${ }_{5}$ The radical anions of $\beta$-lactams, photogenerated in the presence of DABCO as electron donor, undergo cycloreversion via N-C4 bond cleavage, back electron transfer and final C2-C3 bond cleavage, leading to olefins. The involved intermediates are 1,4-radical anions and 1,4-biradicals. The experimental observations are consistent with the results of DFT calculations.

\section{Introduction}

10 The $\beta$-lactam moiety is associated with a broad spectrum of biological properties, including the well-established antibacterial activity. Antibiotics based on this heterocyclic system include penicillins and cephalosporins. ${ }^{1}$

Due to the importance of $\beta$-lactams, their reactivity has 15 attracted considerable attention. However, little is known about the photochemistry of these compounds, which react only sluggishly upon direct irradiation. ${ }^{2}$

The radical anionic cycloreversion of azetidines has been investigated in connection with its possible involvement in the 20 repair of pyrimidine(6-4)pyrimidone photolesions in DNA mediated by photolyases. A non-concerted mechanism appears to operate in the cleavage of the ionized four-membered ring, which is triggered by initial $\mathrm{C}-\mathrm{C}$ or $\mathrm{C}-\mathrm{N}$ bond breaking. From a synthetic point of view, activation of the cycloreversion by 25 injection of one electron may provide a useful complementary strategy to produce new chemistry. ${ }^{3}$

In view of the azetidin-2-one structure of $\beta$-lactams, it should in principle be possible to achieve their cycloreversion under reductive electron transfer (ET) conditions. Recently, the radical

30 anions of some $\beta$-lactams have been photochemically generated using triethylamine as electron donor. However, under these conditions, ring-opening via primary $\mathrm{N}-\mathrm{C} 4$ or $\mathrm{C} 3-\mathrm{C} 4$ bond breaking affords linear amides as the main products. After the initial cleavage step, fast protonation of the resulting 1,4-radical 35 anion by the amine radical cation is preferred over the second bond breaking required to complete cycloreversion. ${ }^{4}$

In this connection, the use of 1,4-diazabicyclo[2,2,2]octane (DABCO) as electron-donor could constitute a proper way to disfavor the protonation step, since this amine contains two

40 bridgehead nitrogen atoms, and therefore the acidity of its radical cation is markedly lower. To prove the concept, the $\beta$-lactams 1ac (Scheme 1) have been submitted to photoinduced ET in the presence of DABCO; as a matter of fact, cycloreversion has been indeed observed as the major reaction pathway.

\section{${ }_{45}$ Results and Discussion}

In a first stage, emission studies were performed to find the appropriate experimental conditions for securing complete quenching of the $\beta$-lactams singlet excited state by DABCO, in order to rule out a direct photoreaction of the substrates. As an 50 example, Figure 1 shows that the fluorescence of $t$-1a (with maximum at $305 \mathrm{~nm}$ ) is quenched in the presence of increasing amounts of DABCO.

55

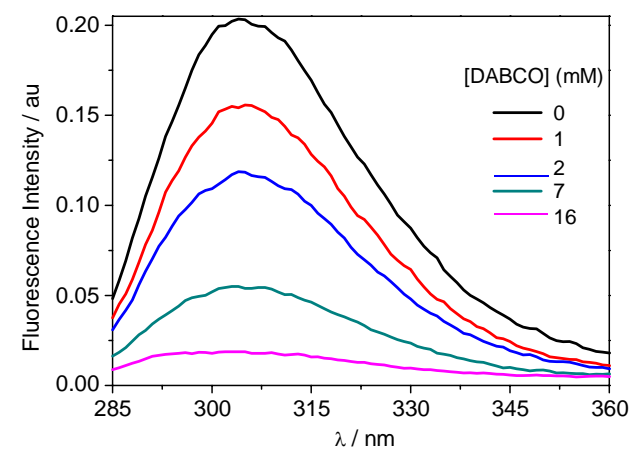

${ }_{65}$ Fig. 1. Fluorescence spectra of $t-1 \mathbf{a}\left(1.6 \times 10^{-4} \mathrm{M}, \mathrm{MeCN}\right.$, air, $\lambda_{\mathrm{exc}}=254$ $\mathrm{nm})$ in the presence of increasing amounts of DABCO.

The ET nature of this process is supported by the free energy change $\left(\Delta \mathrm{G}_{\mathrm{ET}}\right)$ estimated using the Rehm-Weller equation. ${ }^{5}$ Taking into account the oxidation potential of DABCO $(0.57 \mathrm{~V}$ $70 v s . \mathrm{SCE}){ }^{6}$ the reduction potential of $t-1 \mathbf{a}(-2.6 \mathrm{~V} \quad v s . \mathrm{SCE})^{4}$ and the singlet energy of $t$-1a $\left(\mathrm{E}_{\mathrm{S}}=100 \mathrm{kcal} \mathrm{mol}^{-1}\right.$, see Supporting Information) the value of $\Delta \mathrm{G}_{\mathrm{ET}}$ was found to be $-26.8 \mathrm{kcal} \mathrm{mol}^{-1}$, indicating a thermodynamically favored ET process.

Based on these results, irradiation of the $\beta$-lactams was 75 performed in the presence of a large excess of DABCO. Under these conditions, ET quenching of the singlet excited state is complete, and the possibility of a direct photoreaction is prevented. 

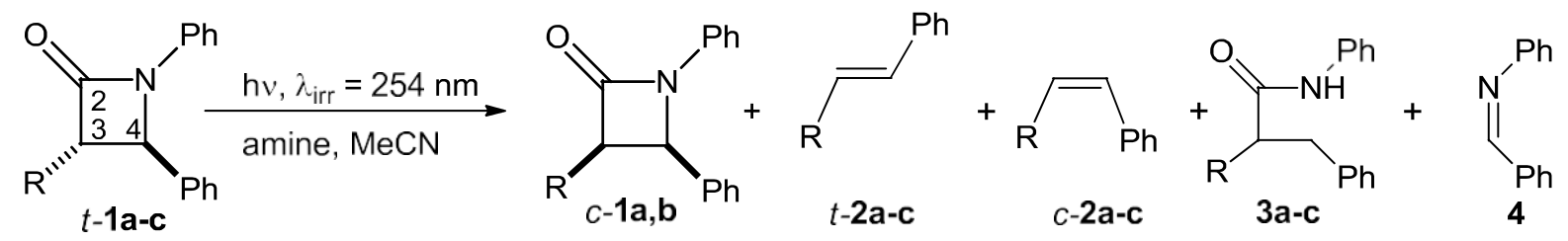
a: $R=$ cyclopropyl
b: $R=n$-propyl
c: $R=$ phenyl
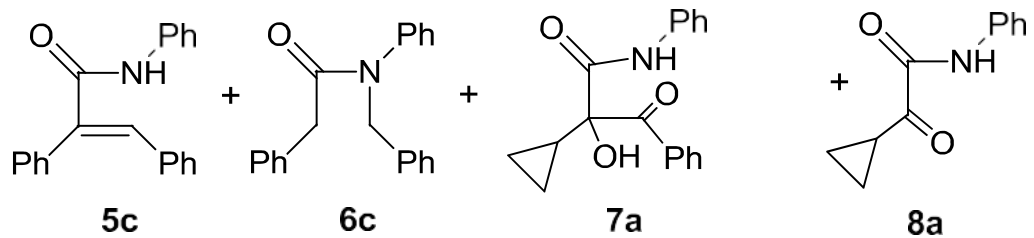

Scheme 1. Photoinduced electron transfer in $\beta$-lactams $t$-1a-c.

Acetonitrile solutions of t-1a-c $(0.01 \mathrm{M})$ containing DABCO were irradiated through quartz at $254 \mathrm{~nm}$, by means of low 5 pressure mercury lamps. Control experiments were performed using triethylamine instead of DABCO and also in the absence of any amine. The course of the reaction was monitored by GC-MS, using biphenyl as internal standard. In general, mass balances were poor at high conversions, due to production of radicals and 10 polymerization. The best compromise between conversion and mass balance was obtained at ca. $30 \mathrm{~min}$ irradiation time; the results are shown in Scheme 1 and

Table 1. Chromatographic separation of the reaction mixtures led to isolation of the photoproducts; their structures were established

15 by spectroscopic analysis and confirmed by X-Ray analysis and/or comparison with authentic samples.

For the sake of clarity, the case of $t$-1a will be considered first, as it constitutes a representative example. In addition, the trends observed with this substrate were qualitatively confirmed in all

20 the investigated $\beta$-lactams. The most remarkable effect of DABCO (Table 1, entry 1) was formation of $t$ - and $c-2 \mathbf{a}{ }^{7}$ formally arising from cycloreversion along the $\mathrm{N}-\mathrm{C} 4$ and $\mathrm{C} 2-\mathrm{C} 3$ bonds.

Conversely, the open-chain amide $\mathbf{3 a}^{4}$ (the only product obtained 25 with triethylamine as electron donor, Table 1, entry 2) was obtained in much lower yield. As a control experiment, irradiation of $t$-1a in the absence of amine resulted in very low conversion, and cycloreversion to 4 along the N-C2 and $\mathrm{C} 3-\mathrm{C} 4$ bonds was observed (Table 1, entry 3 ). Thus, splitting of the 30 neutral excited state corresponds to a retro-Staudinger reaction, ${ }^{2 a}$ while the radical anion generated in the presence of DABCO undergoes cycloreversion with metathesis.

With $t-\mathbf{1} \mathbf{b}^{8}$ and $t-1 \mathbf{c}^{9}$ as substrates, in the presence of DABCO (Table 1 , entries 4 and 7), alkenes $t$ - and $c-\mathbf{2 b}, \mathbf{c}^{10}$ as well as amides $\mathbf{3 b}, \mathbf{c}^{4}$ were again formed. The X-Ray structure of $\mathbf{3 b}$ is shown in Figure 2A; further details of the spectroscopic characterization are given in SI. In the case of $t$-1c, the photomixture contained also imine $\mathbf{4}$ and acrylamide $\mathbf{5 c} .{ }^{11}$ When ${ }_{40}$ DABCO was replaced with triethylamine or in the absence of any amine, the effects were similar to those observed in the case of $t$ 1 (Table 1, entries 5, 6, 8 and 9).

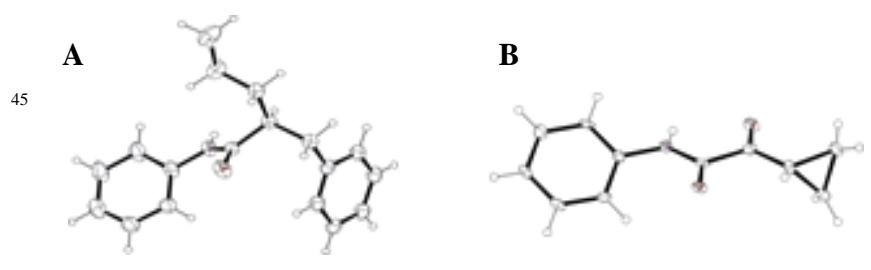

Fig. 2. X-Ray structures of A: $\mathbf{3 b}$ and $\mathbf{B}: \mathbf{8 a}$.

The obtained results can be rationalized as outlined in Scheme 2. Electron transfer from DABCO to the singlet excited state of $t$ 1a-c would afford the distonic radical anions RA-I and/or RA-II. Back electron transfer (BET) to $\mathrm{DABCO}^{\bullet+}$ would give rise to ${ }_{55}$ azabiradicals BR-I ${ }^{12}$ and/or BR-II. ${ }^{13}$ Finally, cycloreversion would be completed by final $\mathrm{C} 2-\mathrm{C} 3$ or $\mathrm{N}-\mathrm{C} 2$ cleavage; the former mode would lead to metathesis, whereas the latter would be equivalent to a formal retro-Staudinger reaction. Radical coupling at BR-I or BR-II would lead back to $t \mathbf{- 1}$ or (after C-C bond 60 rotation) to $c-\mathbf{1}$, while intramolecular disproportionation would explain formation of $\mathbf{5 c}$. The linear amides $\mathbf{3}$ and $\mathbf{6 c}$ could arise either from the radical anions RA-I or RA-II or from biradicals BR-I or BR-II.

Overall, the experimental observations support the initial ${ }_{65}$ hypothesis that the use of DABCO instead of triethylamine should facilitate BET at the radical anionic stage, opening a new pathway ultimately leading to cycloreversion. 
Table 1. Results obtained in the photolysis of $\beta$-lactams 1a-c. ${ }^{a}$

\begin{tabular}{|c|c|c|c|c|c|c|c|c|c|c|}
\hline \multirow[t]{2}{*}{ Entry } & \multirow[t]{2}{*}{ Compound } & \multirow[t]{2}{*}{ Conditions } & \multirow[t]{2}{*}{ Conversion $^{c}$} & \multirow[t]{2}{*}{$\mathrm{MB}^{d}$} & \multicolumn{6}{|c|}{ Product Distribution $^{b}(\%)$} \\
\hline & & & & & $c-1$ & $t-2$ & $c-2$ & 3 & 4 & Other \\
\hline 1 & $t-\mathbf{1 a}$ & $\mathrm{DABCO} / \mathrm{N}_{2}$ & 48 & 88 & 47 & 29 & 9 & 15 & - & - \\
\hline 3 & $t-\mathbf{1 a}$ & No amine $/ \mathrm{N}_{2}$ & 7 & 98 & 43 & - & - & - & 57 & - \\
\hline 4 & $t-\mathbf{1 b}$ & $\mathrm{DABCO} / \mathrm{N}_{2}$ & 33 & 80 & 43 & 26 & 10 & 21 & - & - \\
\hline 7 & $t-1 \mathrm{c}$ & $\mathrm{DABCO} / \mathrm{N}_{2}$ & 64 & 62 & - & 16 & 3 & 43 & 28 & $10^{e}$ \\
\hline 8 & $t-1 \mathrm{c}$ & $\mathrm{Et}_{3} \mathrm{~N} / \mathrm{N}_{2}$ & 87 & 58 & - & - & - & 81 & - & $19^{f}$ \\
\hline 9 & $t-1 \mathrm{c}$ & No amine/ $\mathrm{N}_{2}$ & 25 & 77 & - & - & - & - & 100 & - \\
\hline 10 & $t-\mathbf{1 a}$ & $\mathrm{DABCO} / \mathrm{O}_{2}$ & 25 & 82 & 9 & 21 & 8 & - & 24 & $38^{g}$ \\
\hline
\end{tabular}

${ }^{a} \mathrm{MeCN}, \lambda_{\text {irr }}=254 \mathrm{~nm}, \mathrm{t}=30 \mathrm{~min} ;[$-lactam $]=0.01 \mathrm{M}$, [amine] $=1 \mathrm{M}$. ${ }^{b}$ Determined by GC-MS, using biphenyl as an internal standard; errors were lower than $5 \%$ of the stated values. ${ }^{c}$ Calculated from recovered $\beta$-lactams. ${ }^{d}$ Mass balance. ${ }^{e}$ Compound $5 \mathbf{5} .{ }^{f}$ Compound $\mathbf{6 c} .{ }^{g}$ Includes $7 \mathbf{a}(16 \%)$ and $8 \mathbf{a}(22 \%)$.

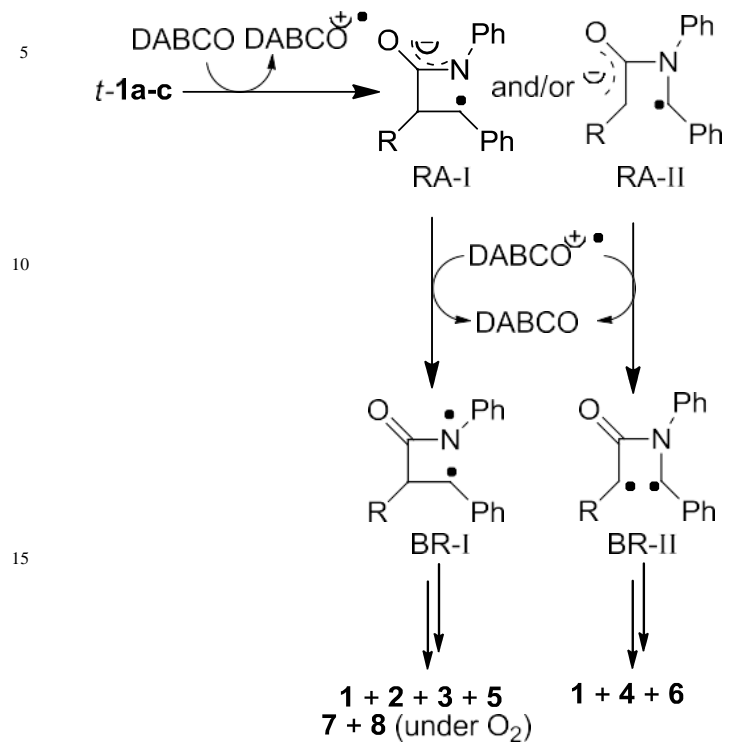

Scheme 2. Mechanistic pathways for cycloreversion of the 20 radical anions generated by photolysis of $\beta$-lactams in the presence of DABCO.

In order to obtain further chemical evidence supporting the involvement of biradicals, molecular oxygen was used as trap. ${ }^{14}$ Thus, $t$-1a was irradiated under oxygen atmosphere in the ${ }_{25}$ presence of DABCO (Table 1, entry 10). As a matter of fact, mass spectral analysis of the photomixture revealed the presence of two additional compounds with molecular ions at $\mathrm{m} / \mathrm{z}=296$ and $190 \mathrm{amu}$. Their chemical structures were unambiguously assigned by full spectroscopic characterization of the isolated ${ }_{30}$ products as 7a and $\mathbf{8 a}$ (see SI) and X-ray diffraction of $\mathbf{8 a}$ (Figure
2B). A control experiment showed that $8 \mathrm{a}$ is a secondary product resulting from irradiation of $7 \mathrm{a}$ under aerobic conditions.

The involved reaction channels were theoretically investigated at the UB3LYP/6-31+G(d)/IEF-PCM(MeCN) computational level.

35 The energy barriers for the first bond cleavage in $\mathbf{1} \mathbf{a}, \mathbf{c}^{\mathbf{-}}$ have been previously reported. ${ }^{4}$ The values obtained now for $\mathbf{1 b}^{\mathbf{}}{ }^{-}$are very similar to those found for $\mathbf{1 a}^{\mathbf{e}}$. The most favorable bond breaking process at $\mathbf{1 b}^{\mathbf{\bullet}}$ is the N1-C4. This confirms that the factor favoring the first bond-breaking at the $\beta$-lactam ring is the 40 presence of phenyl substituents.

At $t-\mathbf{1 a}, \mathbf{b}^{\bullet-}$, N1-C4 bond breaking through TS-Ia,b is highly favored over all other cleavages, due to its low energy barrier (2.0 kcal $\mathrm{mol}^{-1}$ for $t-\mathbf{1 a}^{\mathbf{0}^{-}}$and $3.6 \mathrm{kcal} \mathrm{mol}^{-1}$ for $t-\mathbf{1 b}$ ); therefore this will be the only reaction channel studied. Subsequently, splitting 45 of the resulting intermediates to give the formal metathesis products should occur through TS-I'a,b with high energy barriers (24.2 kcal mol ${ }^{-1}$ from RA-Ia and $26.2 \mathrm{kcal} \mathrm{mol}^{-1}$ from RA-Ib). By contrast, at $t-1 \mathbf{c}^{\bullet-}, \mathrm{N} 1-\mathrm{C} 4$ and $\mathrm{C} 3-\mathrm{C} 4$ bond breaking through TS-Ic and TS-IIc become competitive, due to their similar ${ }_{50}$ energy barriers ( 4.5 and $3.7 \mathrm{kcal} \mathrm{mol}^{-1}$, respectively); splitting of the corresponding radical anions RA-Ic and RA-IIc to give the metathesis or retro-Staudinger reaction products requires again to overcome a high energy barrier through TS-I'c $\left(19.6 \mathrm{kcal} \mathrm{mol}^{-1}\right)$ or TS-II'c $\left(28.0 \mathrm{kcal} \mathrm{mol}^{-1}\right)$, respectively. All these data are 55 represented in Scheme 3.

The intermediates RA-Ia,b,c and RA-IIc can in principle be involved in $\mathrm{BET}$ to $\mathrm{DABCO}^{\circ}$ within the radical ion pair, to yield neutral biradicals BR-Ia,b,c and BR-IIc. To disclose the reactivity of these species, both their singlet and triplet spin states ${ }_{60}$ were studied. As regards the singlet biradicals, all attempts to locate them as stable species failed, and optimizations led directly 
to the final cycloreversion products in a barrierless mode. Other computational methodologies (different DFT functionals, MPn, CASSCF) rendered the same results. Thus, if RA-Ia,b,c experience BET to give the corresponding singlet biradicals, it is 5 reasonable to assume straightforward formation of the metathesis products. Similar results were obtained for RA-IIc and its conversion into the formal retro-Staudinger products. In the triplet biradicals, the energy barriers for bond breaking are 23-29 $\mathrm{kcal} \mathrm{mol}^{-1}$ (for C2-C3) and ca. $30 \mathrm{kcal} \mathrm{mol}^{-1}$ (N1-C2). These high 10 energy barriers indicate that the reaction would not progress towards the formal metathesis or retro-Staudinger products along this pathway. However, the triplet biradicals would be able to react with molecular oxygen, giving rise to trapping products.

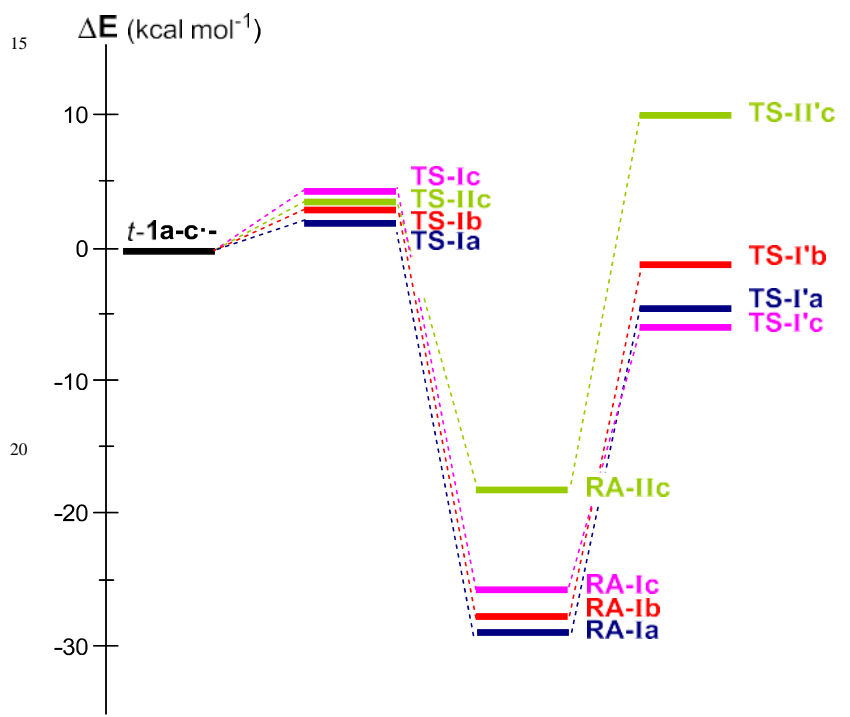

Scheme 3. Relative energies of the transition states and 25 intermediates involved in the splitting of the radical anions of $\beta$-lactams.

\section{Conclusions}

In summary, the cycloreversion of $\beta$-lactams has been photochemically achieved under reductive electron transfer (ET) 30 conditions, using DABCO as electron-donor. Due to the low acidity of $\mathrm{DABCO}^{\bullet+}$, protonation of the 1,4-radical anions obtained after the initial $\mathrm{N}-\mathrm{C} 4$ or $\mathrm{C} 3-\mathrm{C} 4$ bond breaking of $\beta$ lactams is disfavored, and $\mathrm{BET}$ to $\mathrm{DABCO}^{\bullet+}$ is preferred. The resulting 1,4-biradicals undergo $\mathrm{C} 2-\mathrm{C} 3$ or $\mathrm{N}-\mathrm{C} 2$ cleavage, thus 35 completing cycloreversion.

\section{Materials and Methods}

\section{Experimental Details}

Commercial solvents and reagents were used without additional purification. $\beta$-Lactams $t$-1a, $c$-1a, $t$-1b, $t$-1c , and photoproducts $40 t-2 \mathbf{a}, c-2 \mathbf{a}, c-2 \mathbf{b}, 3 \mathbf{a}, 3 \mathbf{c}, 5 \mathbf{c}$ and $\mathbf{6 c}$ have been previously described and characterized (see references in the main text). Compounds $t$-2b, $t$-2c, $c$-2cc, and $\mathbf{4}$ were commercially available. The $\beta$-lactam $c$-1b was synthesized according to the procedure previously published for related compounds.

45

Photoproduct $\mathbf{3 b}$ was isolated from the crude mixture of the photoreaction of $t \mathbf{- 1 b}$ in the presence of DABCO (HPLC, acetonitrile:water 80:20 v/v as eluent). The X-Ray structure and data of $\mathbf{3 b}$ are deposited in the Cambridge Crystallographic Data Centre (CCDC 950918-950919).

${ }_{50}$ Photoproducts $7 \mathbf{a}$ and $\mathbf{8 a}$ were isolated from the crude mixture of the photoreaction of $t$-1a in the presence of DABCO under oxygen atmosphere (HPLC, acetonitrile:water 70:30 v/v as eluent). The X-Ray structure and data of $8 \mathrm{a}$ are deposited in the Cambridge Crystallographic Data Centre (CCDC 958225${ }_{55}$ 958229).

\section{Characterisation of the new compounds}

All new compounds were characterised by ${ }^{1} \mathrm{H}$ and ${ }^{13} \mathrm{C}$ NMR spectroscopy, as well as by high resolution mass spectrometry (HRMS). Their purity was confirmed by gas chromatography ${ }_{60}$ (GC) and high performance liquid chromatograpy (HPLC). A summary of the most relevant data follows.

\section{cis-3-Propyl-1,4-diphenylazetidin-2-one (c-1b)}

${ }_{65}{ }^{1} \mathrm{H}-\mathrm{NMR}\left(400 \mathrm{MHz}, \mathrm{CDCl}_{3}\right)(\delta, \mathrm{ppm}): 0.85(\mathrm{t}, 3 \mathrm{H}, \mathrm{J}=7.4 \mathrm{~Hz})$, $1.45(\mathrm{~m}, 2 \mathrm{H}), 1.68-1.89(\mathrm{~m}, 2 \mathrm{H}), 3.01(\mathrm{~m}, 1 \mathrm{H}), 4.56(\mathrm{~d}, 1 \mathrm{H}, \mathrm{J}=$ $2.4 \mathrm{~Hz}), 6.93(\mathrm{t}, 1 \mathrm{H}, \mathrm{J}=7.2 \mathrm{~Hz}), 7.12-7.30(\mathrm{~m}, 9 \mathrm{H}) ;{ }^{13} \mathrm{C}-\mathrm{NMR}$ $\left(100 \mathrm{MHz}, \mathrm{CDCl}_{3}\right)(\delta, \mathrm{ppm}): 14.1,20.6,31.1,60.6,61.4, \quad 117.0$, 123.8, 126.0, 128.5, 129.1, 129.3, 138.0, 138.4, 168.1; Exact 70 Mass (HRMS): required for $\mathrm{C}_{18} \mathrm{H}_{20} \mathrm{NO}(\mathrm{MH}+)$ : 266.1545; found 266.1456 .

\section{2-Benzyl- $N$-phenylpentanamide (3b)}

${ }^{1} \mathrm{H}-\mathrm{NMR}\left(400 \mathrm{MHz}, \mathrm{CDCl}_{3}\right)(\delta, \mathrm{ppm}): 0.94(\mathrm{t}, \mathrm{J}=7.2 \mathrm{~Hz}, 3 \mathrm{H})$, $751.32-1.58(\mathrm{~m}, 3 \mathrm{H}), 1.78-1.88(\mathrm{~m}, 1 \mathrm{H}), 2.37-2.47(\mathrm{~m}, 1 \mathrm{H}), 2.81$ $(\mathrm{dd}, \mathrm{J}=13.5 \mathrm{~Hz}, \mathrm{~J}=5.3 \mathrm{~Hz}, 1 \mathrm{H}), 2.99(\mathrm{dd}, \mathrm{J}=13.5 \mathrm{~Hz}, \mathrm{~J}=9.4$ $\mathrm{Hz}, 1 \mathrm{H}), 6.80$ (s, 1H), 7.07 (t, J = 7.2 Hz 1H,), 7.18-7.33 (m, 9H); ${ }^{13} \mathrm{C}-\mathrm{NMR}\left(100 \mathrm{MHz}, \mathrm{CDCl}_{3}\right)(\delta, \mathrm{ppm}): 14.2,20.9,35.1,39.6$, $51.1,120.3,124.4,126.5,128,7,128.9,129.0,137.6,139.9$, 80 173.5; Exact Mass (HRMS): required for $\mathrm{C} 18 \mathrm{H} 22 \mathrm{NO}(\mathrm{MH}+$ ): 268.1701; found 268.1689.

\section{2-Cyclopropyl-2-hydroxy-3-oxo- $N, 3$-diphenylpropanamide (7a)}

85

${ }^{1} \mathrm{H}-\mathrm{NMR}\left(400 \mathrm{MHz}, \mathrm{CDCl}_{3}\right)(\delta, \mathrm{ppm}): 0.32-0.43$ (m, 2H), $0.48-$ $0.55(\mathrm{~m}, 1 \mathrm{H}), 0.69-0.76(\mathrm{~m}, 1 \mathrm{H}), 1.97-2.04(\mathrm{~m}, 1 \mathrm{H}), 5.16(\mathrm{~s}, 1 \mathrm{H})$, $7.13(\mathrm{t}, J=7.4 \mathrm{~Hz}, 1 \mathrm{H}), 7.30-7.35(\mathrm{~m}, 2 \mathrm{H}), 7.47-7.62(\mathrm{~m}, 5 \mathrm{H})$, $8.43(\mathrm{~d}, J=7.4 \mathrm{~Hz}, 2 \mathrm{H}), 8.83(\mathrm{~s}, 1 \mathrm{H}) ;{ }^{13} \mathrm{C}-\mathrm{NMR}(100 \mathrm{MHz}$, ${ }_{90} \mathrm{CDCl}_{3}$ ) $(\delta, \mathrm{ppm}): 0.6,1.3,18.0,82.2,120.0,124.9,128.5,129.2$, 131.4, 133.7, 134.0, 137.2, 168.7, 199.7; Exact Mass (HRMS): required for $\mathrm{C}_{18} \mathrm{H}_{18} \mathrm{NO}_{3}\left(\mathrm{MH}^{+}\right)$: 296.1287; found 296.1284.

\section{2-Cyclopropyl-2-oxo- $N$-phenylacetamide (8a)}

95

${ }^{1} \mathrm{H}-\mathrm{NMR}\left(400 \mathrm{MHz}, \mathrm{CDCl}_{3}\right)(\delta, \mathrm{ppm}): 1.21-1.27(\mathrm{~m}, 4 \mathrm{H}), \quad 3.17-$ $3.24(\mathrm{~m}, 1 \mathrm{H}), 7.18(\mathrm{t}, J=7.4 \mathrm{~Hz}, 1 \mathrm{H}), 7.35-7.41(\mathrm{~m}, 2 \mathrm{H}), 7.66(\mathrm{~d}$, $J=7.4 \mathrm{~Hz}, 2 \mathrm{H}), 8.78(\mathrm{~s}, 1 \mathrm{H}) ;{ }^{13} \mathrm{C}-\mathrm{NMR}\left(100 \mathrm{MHz}, \mathrm{CDCl}_{3}\right)(\delta$, ppm): $15.0,15.4,119.9,125.3,129.4,136.6,157.8$, 198.6: Exact 100 
190.0869 .

\section{Steady-State Fluorescence}

Fluorescence and excitation spectra were carried out using a JASCO FP-8500 spectrofluorimeter equipped with a 150 W 5 xenon lamp. The samples were placed into quartz cells of $1 \mathrm{~cm}$ path length. Compound concentrations were fixed as indicated.

\section{Computational methods}

DFT calculations have been performed using the B3LYP exchange-correlation functional together with the standard 6${ }_{10} 31+\mathrm{G}(\mathrm{d})$ basis set. For the studied open-shell species, the spinunrestricted formalism (UB3LYP) was employed. The S2 expectations for the doublet states of all radical anions showed an ideal value of 0.750 after spin annihilation and these values for triplet states were 2.000, so the geometries and the energetics are

15 reliable for this study. Optimizations were carried out using the Berny analytical gradient optimization method. The stationary points were characterized by frequency calculations in order to verify that the transition structures (TSs) had only one imaginary frequency. The intrinsic reaction coordinate (IRC) path was

20 traced in order to check the energy profiles connecting each TS with the two associated minima of the proposed mechanism, using the second order González-Schlegel integration method. The electronic structures of stationary points were analysed by the natural bond orbital (NBO) method. The solvent effects on 25 the mechanism of the ring splitting have been considered using a self-consistent reaction field (SCRF) method based on the polarizable continuum model (PCM) of Tomasi's group. As the solvent used in the experimental work was acetonitrile, we have selected its dielectric constant $\mathrm{E}=36.64$. Thermodynamic 30 calculations were made with the standard statistical thermodynamics at $298.15 \mathrm{~K}$ and $1 \mathrm{~atm}$. Harmonic vibrational frequencies were scaled by a factor of 0.96 . All calculations were carried out with the Gaussian09 suite of programs.

\section{Acknowledgements}

35 Financial support from the Spanish Government (CTQ201014882, SEV-2012-0267, BES-2011-043706, JCI-2010-06204), from CSIC (JAEDOC 101-2011 co-funded by FSE) and from the Generalitat Valenciana (PROMETEOII/2013/005) is gratefully acknowledged. J. A. S. acknowledges the computational facilities 40 provided by the Theoretical Computational Chemistry Group of Prof. L. R. Domingo at the Universitat de València).

\section{Notes and references}

${ }^{a}$ Departamento de Química/Instituto de Tecnología Química UPV-CSIC, Universitat Politécnica de València, Camino de Vera s/n, 46022,

45 Valencia, Spain E-mail: mcjimene@qim.upv.es; mmiranda@qim.upv.es

$\dagger$ Electronic Supplementary Information (ESI) available: [Additional experimental details, computational methods, spectroscopic characterization, X-Ray data of $\mathbf{3 b}$ and $\mathbf{8 a}$, and geometries of the stationary points involved in several reactions; UB3LYP/6-31+G(d)/IEF${ }_{50} \mathrm{PCM}(\mathrm{MeCN})$ Cartesian coordinates.]. See DOI: 10.1039/b000000x/

(1) (a) von Nussbaum, F.; Brands, M.; Hinzen, B.; Weigand, S.; Häbich, D. Angew. Chem., Int. Ed. 2006, 45, 5072-5129; (b) Singh, G. S.
Mini-Rev. Med. Chem. 2004, 4,69-92; (c) Singh, G. S. Mini-Rev. Med. Chem. 2004, 4, 93-109; (d) Buynak, J. D. Curr. Med. Chem. 2004, 11, 1951-1964; (e) Veinberg, G.; Vorona, M.; Shestakova, I.; Kanepe, I.; Lukevics, E. Curr. Med. Chem. 2003, 10, 1741-1757; (f) Kidwai, M.; Sapra, P.; Bhushan, K. R. Curr. Med. Chem. 1999, 6, 195-215; (g) Chemistry and Biology of $\beta$-Lactam Antibiotics; Morin,

60 R. B., Gorman, M., Eds.; Academic Press: New York, 1982; pp 1-3; (h) Nathwani, D.; Wood, M. J. Drugs 1993, 45, 866-894.

(2) (a) Fischer, M. Chem. Ber. 1968, 101, 2669-2678; (b) Fabre, H. Ibork, H.; Lerner, D. A. J. Pharm. Sci. 1994, 83, 553-558; (c) Rossi, E.; Abbiati, G.; Pini, E. Tetrahedron 1999, 55, 6961-6970; (d)

65 Alcazar, R.; Ramirez, P.; Vicente, R.; Mancheño, M. J.; Sierra, M. A.; Gomez-Gallego, M. Heterocycles 2001, 55, 511-521; (e) Mukerjee, A. K.; Singh, A. K. Synthesis 1975, 547-589; (f) Mukerjee, A. K.; Singh, A. K. Tetrahedron 1978, 34,1731-1767.

(3) Pérez-Ruiz, R.; Jiménez, M. C.; Miranda, M. A. Acc. Chem. Res. 2014, 47, 1359-1368.

(4) Pérez-Ruiz, R.; Sáez, J. A.; Domingo, L. R.; Jiménez. M. C.; Miranda, M. A. Org. Biomol. Chem. 2012, 10,7928-7932.

(5) Rehm, D.; Weller, A. Isr. J. Chem., 1970, 8, 259-271.

(6) Kavarnos, G. J.; Turro, N. J. Chem. Rev. 1986, 86, 401-449.

75 (7) (a) Gandon, V.; Bertus, P.; Szymoniak, J. Eur. J. Org. Chem. 2000, 3713-3719; (b) Wang, S. C.; Troast, D. M.; Conda-Sheridan, M.; Zuo, G.; LaGarde, D.; Louie, J.; Tantillo, D. J. J. Org. Chem. 2009, 74, 7822-7833.

(8) Kashima, C.; Fukusaka, K.; Takahashi, K. J. Heterocyclic. Chem. 1997, 34, 1559-1565.

(9) Andreu, I.; Delgado, J.; Espinos, A.; Perez-Ruiz, R.; Jimenez, M. C.; Miranda, M. A. Org. Lett. 2008, 10,5207-5210.

(10) Alkenes $t-\mathbf{2 b}$ and $t / c-2 \mathbf{c}$ are commercially available. For $c-\mathbf{2 b}$ see: Belger, C.; Neisius, N. M.; Plietker, B. Chem. Eur. J. 2010, 16, 12214-12220.

(11) Eicher, T.; Böhm, S.; Ehrhardt, H.; Harth, R.; Lerch, D. Liebigs Ann. Chem. 1981, 765-788.

(12) (a) Mazzocchi, P. H.; Thomas, J. J. J. Am. Chem. Soc. 1972, 94, 8281-8282; (b) Lewis, F. D.; Wagner-Brennan, J. M.; Miller, A. M.

$90 \quad$ Can. J. Chem. 1999, 77, 595-604; (c) Platz, M. S.; Burns, J. R. J. Am. Chem. Soc. 1979, 101, 4425-4426; (d) Leo, E. A.; Domingo, L. R.; Miranda, M. A.; Tormos, R. J. Org. Chem. 2006, 71, 4439-4444.

(13) Miranda, M. A.; Font-Sanchis, E.; Perez-Prieto, J.; Scaiano, J. C. J. Org. Chem. 1999, 64, 7842-7845.

95 (14) (a) Wilson, R. M. Organic Photochemistry; Padwa, A., Ed.; Marcel Dekker: New York, 1985; Vol. 7, Chapter 5, pp 339-467; (b) Adam, W.; Grabowski, S.; Wilson, R. M. Acc. Chem. Res. 1990, 23, 165172. 